\title{
Forecasting of China's solar PV industry installed capacity and analyzing of employment effect: based on GRA-BiLSTM model
}

\author{
Bingchun Liu ${ }^{1} \cdot$ Chengyuan Song ${ }^{1} \cdot$ Qingshan Wang ${ }^{2} \cdot$ Yuan Wang ${ }^{3}$ \\ Received: 29 April 2021 / Accepted: 9 August 2021 / Published online: 19 August 2021 \\ (C) The Author(s), under exclusive licence to Springer-Verlag GmbH Germany, part of Springer Nature 2021
}

\begin{abstract}
With the acceleration of China's energy transformation process and the rapid increase of renewable energy market demand, the photovoltaic (PV) industry has created more jobs and effectively alleviated the employment pressure of the labor market under the normalization of the epidemic situation. First, to accurately predict China's solar PV installed capacity, this paper proposes a multi-factor installed capacity prediction model based on bidirectional long short-term memory-grey relation analysis. The results show that, the MAPE value of the GRA-LSTM combined model established in this paper is 5.995, compared with the prediction results of other models, the prediction accuracy of the GRA-BiLSTM model is higher. Second, the BiLSTM model is used to forecast China's installed solar PV capacity from 2020 to 2035. The forecast results show that China's newly installed solar PV capacity will continue to grow and reach $2833 \mathrm{GW}$ in 2035 . Third, the employment number in China's solar PV industry during 2020-2035 is predicted by the employment factors (EF) method. The results show that the energy transition in China during 2020-2035 will have a positive impact on the future stability and growth of the labor market in the solar PV industry. Overall, an accurate forecast of solar PV installed capacity can provide effective decision support for planning electric power development strategy and formulating employment policy of solar PV industry.
\end{abstract}

Keywords PV installed capacity $\cdot$ Employment effect $\cdot$ BiLSTM

\section{Introduction}

Global climate change has promoted the rapid development and wide application of renewable energy in the world, and the renewable energy industry has gradually become the focus of attention of various countries (Dga et al. 2019). As a widely used renewable energy, solar energy has the characteristics of wide distribution, mature technology application, reliability, and low construction cost. It will become an important growth pole in future energy development (Kabir et al. 2018). As

Responsible Editor: Philippe Garrigues

Qingshan Wang

tigermountain@yeah.net

1 School of Management, Tianjin University of Technology, Tianjin 300384, People's Republic of China

2 School of Humanities, Tianjin Agricultural University, Tianjin 300380, People's Republic of China

3 School of Environmental Science and Engineering, Tianjin University, Tianjin 300072, People's Republic of China early as the 1970s, developed countries such as the USA, Germany, and Japan implemented many incentive policies to promote solar power generation and the construction of solar PV power stations. As the largest developing country, China has formulated several encouraging policies to expand the market scale of domestic solar PV power generation since its formal large-scale launch in 2009 , including promoting several solar PV power plant concession projects in 2009, implementing the online tariff policy in 2011, and formulating the solar PV industry development action plan in 2018. These policies have further promoted the development quality and efficiency of the solar PV industry achieving sustainable and healthy development driven by photovoltaic intelligent innovation.

With the strong support of the policy, China's solar PV industry has achieved breakthrough progress in the past decade, and its social welfare effect has been gradually reflected. China's annual new installed capacity and the cumulative installed capacity of solar PV have seen significant growth. At the same time, the growth rate of its new installed capacity is significantly higher than the world average, as shown in Fig 1. By 2020, China's cumulative installed 
Fig. 1 The growth rate of installed capacity of PV industry in the world and China

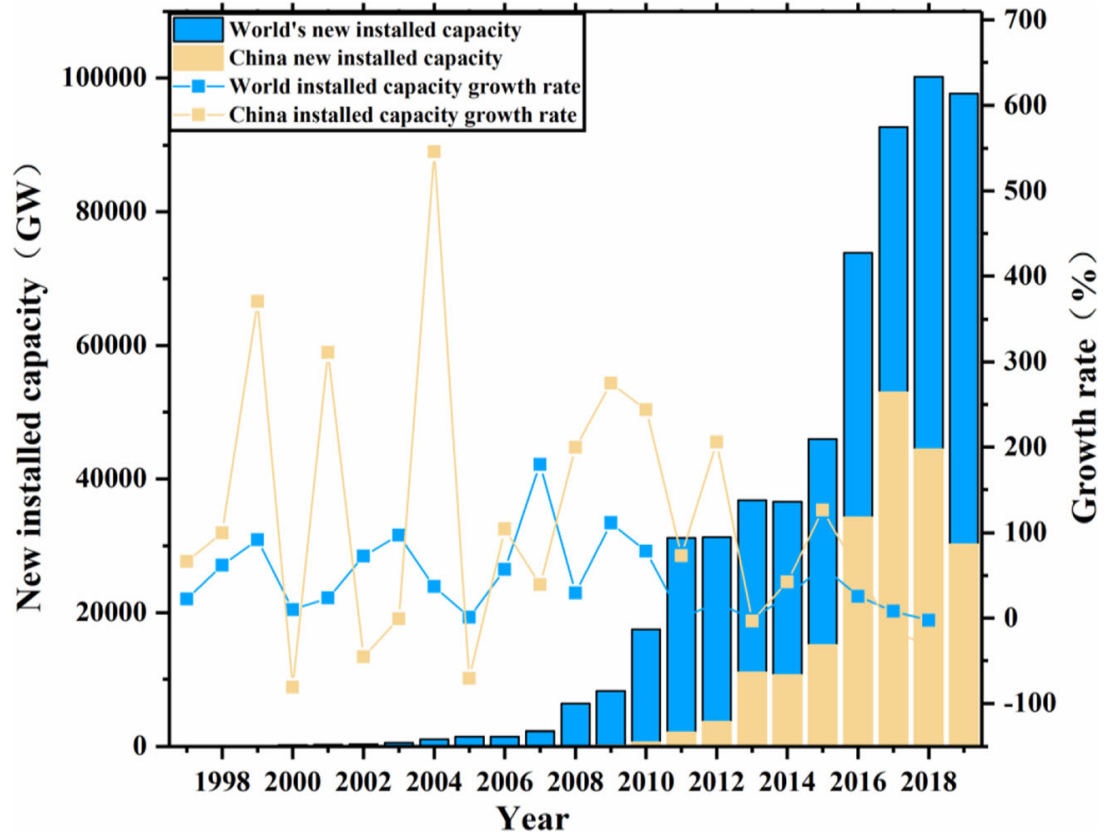

capacity of solar PV power generation has reached 203GW, ranking first in the world. At the Climate Ambition Summit in 2020, the total installed capacity of wind power and solar power will reach more than 1.2 billion $\mathrm{kW}$ in 2030 , which fully demonstrates China's strength and determination to actively respond to climate change. By the end of 2019, the total number of employees in China's solar PV industry has reached 4.57 million, including 3.75 million in the solar PV power generation industry and 820,000 in the solar heating industry. Since the solar PV poverty alleviation work was carried out in 2014, China has built 26.36 million $\mathrm{kW}$ of solar PV poverty alleviation power stations, benefiting 60,000 poor villages and 4.15 million poor households, encouraging poor labor to work nearby, and effectively alleviating the employment pressure in poor areas. In 2020, $80 \%$ of the income from PV poverty alleviation will be used to pay the poor people for public welfare jobs and the poor households for public welfare construction.

Reasonable installed capacity is very important for the solar PV industry to enter the stage of scale economy, so the key problem of accurate prediction of installed capacity needs to be solved. The too fast installation will lead to overcapacity and an "abandoned light" problem; slow and insufficient installation will lead to China's economic growth lower than expected. The forecasting of installed capacity is a nonlinear problem under the influence of multiple factors. Therefore, to accurately predict China's installed solar PV capacity, it is necessary to fully consider the influencing factors of China's installed solar PV capacity and screen out the indicators with a strong correlation with installed capacity. The deep neural network has good abilities of nonlinear mapping, selflearning and self-adaptive, associative memory, and parallel information processing. It shows good applicability in processing time series data in different scenarios. When dealing with the problem of nonlinear time-series prediction, a deep neural network effectively extracts data features through multi-layer nonlinear transformation to achieve accurate prediction of output variables. Based on this, a multi-factor prediction model for GRA-BiLSTM solar PV installed capacity is established in this paper. Accurate prediction results can effectively schedule and plan the energy system, improve the stability of the energy system, and reduce the overall operating cost. With the reduction of a series of solar PV subsidy funds, the public has become concerned about the employment situation of the solar PV industry, and the recognition of the solar PV industry is not high (Yan et al. 2020; Dong et al. 2020). At the same time, the government also fails to fully recognize the positive role of the rapid development of the solar PV industry in China's employment, and lacks corresponding employment support policies to encourage the public to actively participate in the development of the solar PV industry. Due to the late start of China's solar PV market, most of China's solar PV enterprises pursue the scale of production capacity and ignore the professional skills training of employees. The overall value chain of the solar PV industry is still at the low-end level. Compared with other countries' solar PV industry, it lacks core competitiveness and advantages. In China, the cultivation of solar PV talents is still at the level of secondary colleges or vocational and technical colleges. Although domestic well-known colleges have some research in the field of solar PV, they have not carried out systematic teaching on a large scale. At present, most of the technical talents are from related industries, such as the semiconductor industry, electronic industry, and related materials industry 
after entering solar PV enterprises; these transformation personnel still need a long time of technology running in, technology growth, and technology maturity. And with the continuous expansion of the scale of the solar PV industry, the gap of human resources will be further expanded. Based on this, this paper uses the EF method to estimate the employment number of different jobs in the solar PV industry in the future, which provides the basis for the development of solar PV professional talent training direction and employment policy.

The contribution of this study mainly includes three aspects: (1) The multi-factor prediction model of solar PV installed capacity based on GRA-BiLSTM is established. For the first time, the deep learning technology is introduced into the forecast of installed capacity. (2) Based on the prediction model of GRA-BiLSTM, this paper predicts the installed photovoltaic capacity in China from 2020 to 2035, points out the characteristics of different stages of the development of China's photovoltaic industry, and analyzes the reasons. This can be used as a reference for the management decision of electric power enterprises and the policy formulation of the government. (3) According to the forecast results of installed capacity, the EF (employment factors) method is used to estimate the employment of China's solar PV industry from 2020 to 2035. Combined with the prediction results, the social welfare effect brought by the rapid development of photovoltaic industry is explained. (4)The corresponding suggestions are put forward according to the forecast results, including the government should fully understand the positive role of the rapid development of the solar PV industry in China's employment, improve the existing preferential policies for solar PV employment, increase financial support for solar photovoltaic projects in poor areas, and strengthen educational training of relevant professionals in the photovoltaic industry.

The paper is organized as follows. "Literature review" section" introduces the methods and indicators used by different scholars to predict installed capacity, as well as the methods to calculate renewable energy jobs. "Methodology and data" section introduces the research framework, methods, and data of the paper. The prediction implementation and results analysis are shown in "Empirical study" section, and "Discussion" section discusses the forecast results in the context of the broader scientific literature. "Conclusions and policy implications" section summarize the research results of the paper and put forward corresponding policy suggestions.

\section{Literature review}

\section{Forecast of installed capacity}

The prediction of solar PV installed capacity is a complex nonlinear problem. The traditional prediction model can be divided into a single factor or multi-factor model according to the data structure. Statistical analysis method is applied to early capacity prediction. Li et al. (2018) used four-time series prediction methods including MGM, ARIMA, GM-ARIMA, and NMGM to predict coal and electricity installed capacity in China. Şahin (2020) predicted Turkish total installed capacity and electricity of renewable energy and hydropower energy from 2019 to 2030 through the fractional-order nonlinear Bernoulli model. However, due to the exponential growth trend of solar PV-related energy production indicators, including power generation and installed capacity, traditional statistical methods cannot meet the complex and changeable data prediction needs. Assuming that the best predictor of installed capacity is historical data, without considering other influencing factors, machine learning methods such as support vector regression (SVR) and artificial neural network (ANN) can also achieve univariate time series prediction with historical values as input variables. The above model has been widely used to predict electricity consumption (Khan et al. 2020), electricity price (Uniejewski and Weron 2021), electricity generation (Or et al. 2020), and electricity market investment (Marques et al. 2019).

Although the single-factor forecasting model has been widely used in forecasting, the multi-factor forecasting model is more feasible. The multi-factor forecasting model identifies the economic, social, and environmental factors associated with the prediction indicators, and further constructs the functional relationship between the influencing factors and the prediction indicators (Wang et al. 2018). Celik and Zgür (2020) analyzed the relationship between the installed capacity of solar PV power generation and GDP and population in Turkey, and Nemet et al. (2020) discussed the impact of the solar feed-in tariff on the installation of installed capacity. When carrying out the installed capacity, we should fully consider the impact of macroeconomic indicators on the installed capacity (Bulut and Menegaki 2020), including GDP, population, and industrial added value. Most of the indicator data results come from various official and authoritative institutions. Since the end of the 1980s or the beginning of the 1990s, the statistics of installed capacity and related conditions in various regions have generally started. Due to the small sample size and the non-linear data change, some statistical multi-factor forecasting models, such as the vector error correction model or multiple regression model, have poor applicability. Considering the nonlinear characteristics of the data, the machine learning method is introduced into the prediction of installed capacity. According to the prediction accuracy of the model, the predictability of national installed capacity is discussed, and the influence of input index on output result is calculated (Feng et al. 2021). SVR has been widely used in a small sample and high-dimensional data (Duan et al. 2018). Compared with the traditional regression model, artificial neural network prediction can have better prediction performance. In the case of missing data, the method 
based on SVR can effectively deal with the problem of missing data (Luo et al. 2018; Li et al. 2018). To predict the future solar installed capacity, Liu et al. (2020) tested the applicability of the CEEMD-ABC-LSSVM model to this kind of problem through the historical solar PV installed capacity data. At the same time, based on good accuracy, the model was further used to predict the future solar PV installed capacity growth.

According to the literature analysis, the existing installed capacity prediction is mainly based on traditional statistical methods and machine learning methods, including singlefactor prediction model and multi-factor forecasting model. Among them, the multi-factor forecasting model can predict the output index according to the identification of relevant influencing factors and improve the accuracy and adaptability of the model prediction under the influence of multi factors. At the same time, the existing researches are mostly based on machine learning methods to build multi-factor models and make predictions and fail to apply deep learning to the prediction of installed capacity. Compared with the traditional statistical methods and machine learning methods, deep learning technology solves the problem that it is difficult to deal with nonlinear data in traditional statistics, and makes up for the defect that machine learning can only achieve local optimization. Deep learning algorithm is far superior to other types of algorithms in depth function extraction ability, and has great potential in improving accuracy. Compared with other methods, the biggest advantage of deep learning is that it can effectively reduce the errors caused by data redundancy and random noise through the input function of the model (Zhu et al. 2019), and combine with the network structure composed of multiple hidden layers to extract the hierarchical characteristics of data and improve the robustness of the model. Compared with other methods, deep learning has greater shallow learning potential, helps to solve the problem of small samples, and improves the generality of the model through feature extraction of data (Feng and Chen 2021). Zeng et al. (2017a) applies deep learning technology to national energy consumption prediction, which effectively solves the problem of small amount of data at the national level.

\section{The impact of renewable energy on employment}

In recent years, renewable energy has made great contributions to providing new jobs during the energy transformation period under the influence of environmental policies and energy security issues. The International Renewable Energy Agency estimates that the number of renewable energy- related employment will increase from 10.3 million in 2017 to about 16.7 million in 2030 (IRENA, 2018). At the same time, many studies show that the use of renewable energy power generation creates more employment opportunities than traditional power plants (Stephens 2019). It is estimated that the jobs created by renewable energy are 1.7 to 14.7 times that of natural gas power plants and 4 times that of coal-fired power plants (Cameron and Bob 2015). Renewable energy has contributed to the creation of more employment opportunities in the markets of various countries. Take the USA as an example, solar power generation accounts for only $1 \%$ of the total power generation, while coal accounts for about $26 \%$ of the power structure. However, compared with the highly automated coal industry, the number of jobs in the solar PV industry has doubled (U.S. Department of Energy, 2017).

Most of the existing literature focus on the impact of renewable energy on employment in developed countries such as the USA and Europe. Dvořák et al. (2017) evaluated the capacity of Czech renewable energy sectors to provide jobs, and the results showed that solar energy and biomass energy could provide more jobs. The employment rate of solar PV construction and operation is 7.14 jobs per MW and 0.12 jobs per MW (Heavner and Chiaro 2003). Renewable energy will have a positive impact on the Dutch economy, creating nearly 50,000 new jobs (Bulavskaya and Reynes 2018). However, the survey results of this type of report are not suitable for the calculation of employment situation in other regions, and the analysis value of studying employment situation in other countries is limited.

In the research of measuring the impact of renewable energy on employment, three methods are mainly used: economic input-output model (I/O), computable general equilibrium model (CGE), and spreadsheet analysis method. I/O model can fully consider the potential employment impact of renewable energy diffusion (Panagiotis and Leonidas 2018). I/O model can be used to determine the change of a specific industry according to its impact on other industries, to evaluate the multiplier effect of direct employment and indirect employment (Hondo and Moriizumi 2017; Jiang et al. 2019). CGE model emphasizes the input-output linkage or correlation effect of industry ( $\mathrm{Li}$ et al., 2020), which establishes a quantitative relationship between various components of the economy so that we can investigate the impact of disturbance from one part of the economy on the other part of the economy (Mu et al. 2018). Compared with the CGE model, the spreadsheet analysis model is generally considered to be more transparent. It usually relies on the interview or questionnaire survey of the relevant departments of the renewable energy industry, and obtains the employment coefficient of each department through simple calculation, which can be directly applied to the calculation of employment in other regions (Bongers et al. 2020). This model often ignores jobs that are not directly related to a particular industry. Therefore, the results of the model do not include indirect employment and induced employment. Some scholars also apply econometric methods such as vector error correction model and panel data analysis to the impact of renewable energy on employment (Arvanitopoulos and Agnolucci 2020), analyze the relationship between renewable energy installed capacity and job 
creation, and propose that every $1 \%$ increase in renewable energy generation capacity will increase employment by 0.48\% (Proença and Fortes 2020).IRENA and Greenpeace International use the work intensity or employment factor (Vosniadou et al. 2018) to measure the number of jobs gained from an increase in capacity or investment in given energy technology, and the results are highly transparent (Zhou et al., 2020). Rutovitz and Atherton (2009) elaborate on the $\mathrm{EF}$ approach to job creation potential in a low-carbon energy environment of the future as proposed in the Greenpeace Energy Plan. Rutovitz et al. (2015) aim to further improve the methodology and provide a more comprehensive analysis of the net jobs created during the energy transition to assess the job creation potential of complementary storage technologies. This study also includes an estimate of decommissioning jobs for various generation technologies created during the energy transition to 2050 .

According to the literature analysis, during the period of energy transformation, the rapid development of renewable energy plays a positive role in alleviating the employment pressure of the local labor market, but the existing research on the employment effect of the PV industry is mainly concentrated in developed countries, and the in-depth research on the employment effect of China's PV industry is very little.

\section{Methodology and data}

\section{GRA-BiLSTM}

GRA-BiLSTM model is an intelligent network model that combines the advantages of grey relational degree analysis and a bidirectional long short-term memory neural network. The approximate correlation between the reference series and several comparison series is determined through the correlation analysis, and the indicators with higher correlation are screened out to enter the learning model. Finally, the predicted value of PV installed capacity is output, laying a foundation for the calculation of the number of employments. The research steps are shown in Figure 2. GRA-BiLSTM model can not only analyze the correlation characteristics among the original indicators by using the grey relational degree method, but also combine the self-learning and fault-tolerant ability of the neural network, which can improve the accuracy of the prediction of solar PV installed capacity and the efficiency of deep learning.

\section{BiLSTM}

To improve the learning ability of the traditional long shortterm memory (LSTM) model, the BiLSTM model takes into account the bidirectional relationship of input data in the time structure, instead of only using a single direction of input processing through the LSTM gate, and processes the current time series data with full consideration of the next information. This two-way processing obtains more structural information through the gate mechanism and enhances the way of information intelligence. The BiLSTM model encodes information in sequence to obtain the information characteristics of the data before and after, to improve the generalization ability. The LSTM unit starts from the input sequence, and the reverse form of the input sequence has been integrated into the LSTM network. The BiLSTM model generated by the forward $h_{t}$ and backward layers $h_{t}^{\prime}$ is shown in Fig 3.

Calculate forward from time 1 to time $t$ in the forward layer to get and save the output of forward at each time. Calculate backward from time $t$ to time 1 in the backward layer to get and save the output of backward layer at every moment. Finally, the final output can be obtained at each moment by combining the output results at the corresponding moments of the forward layer and the backward layer. The mathematical expression is shown in Eqs. (1)-(3).

$h_{t}=f\left(w_{1} x_{t}+w_{2} h_{t-1}+b\right)$

$h_{t}^{\prime}=f\left(w_{3} x_{t}+w_{5} h_{t-1}+b^{\prime}\right)$

$y_{t}=w_{4} h_{t}+w_{6} h_{t}^{\prime}+b_{y}$

Where $w_{1}-w_{6}$ is the corresponding weight coefficient; $h_{t}, h_{t}^{\prime}$ ,$x_{t}$, and $y_{t}$, are respectively the vectors forward propagation, backward propagation, input layer, and output layer; $b, b^{\prime}$, and $b_{y}$ are the corresponding bias vectors.

\section{Gray relation analysis}

Grey relation analysis (GRA) is a multi-factor statistical analysis method, which measures the relationship of each influencing factor of the selected research index according to the similarity or difference degree of development trend among factors (Wei 2010; Mahmoudi et al. 2020). The GRA method has a small amount of calculation, which is suitable for both sample size and regularity (Feng et al. 2021). Set reference sequence as $x_{0}=\left\{x_{0}(1), x_{0}(2), \cdots, x_{0}(m)\right\}$, where $n$ is the number of input data, comparison sequence $x_{i}=\left\{x_{i}(1)\right.$, $\left.x_{i}(2), \cdots, x_{i}(n) \mid i=0,1,2, \cdots, m-1\right\}$, where $m$ is the number of all indicators. The selected index series are standardized, and the correlation coefficient is obtained according to formula 4 . Where $\varepsilon$ is the discriminant coefficient, $0<\varepsilon<1$, it is used to reduce the influence of excessive maximum value on the distortion of correlation coefficient; $\xi_{i}(k)$ represents the correlation coefficient of reference sequence and comparison 
Fig. 2 GRA-BiLSTM prediction model logic structure diagram
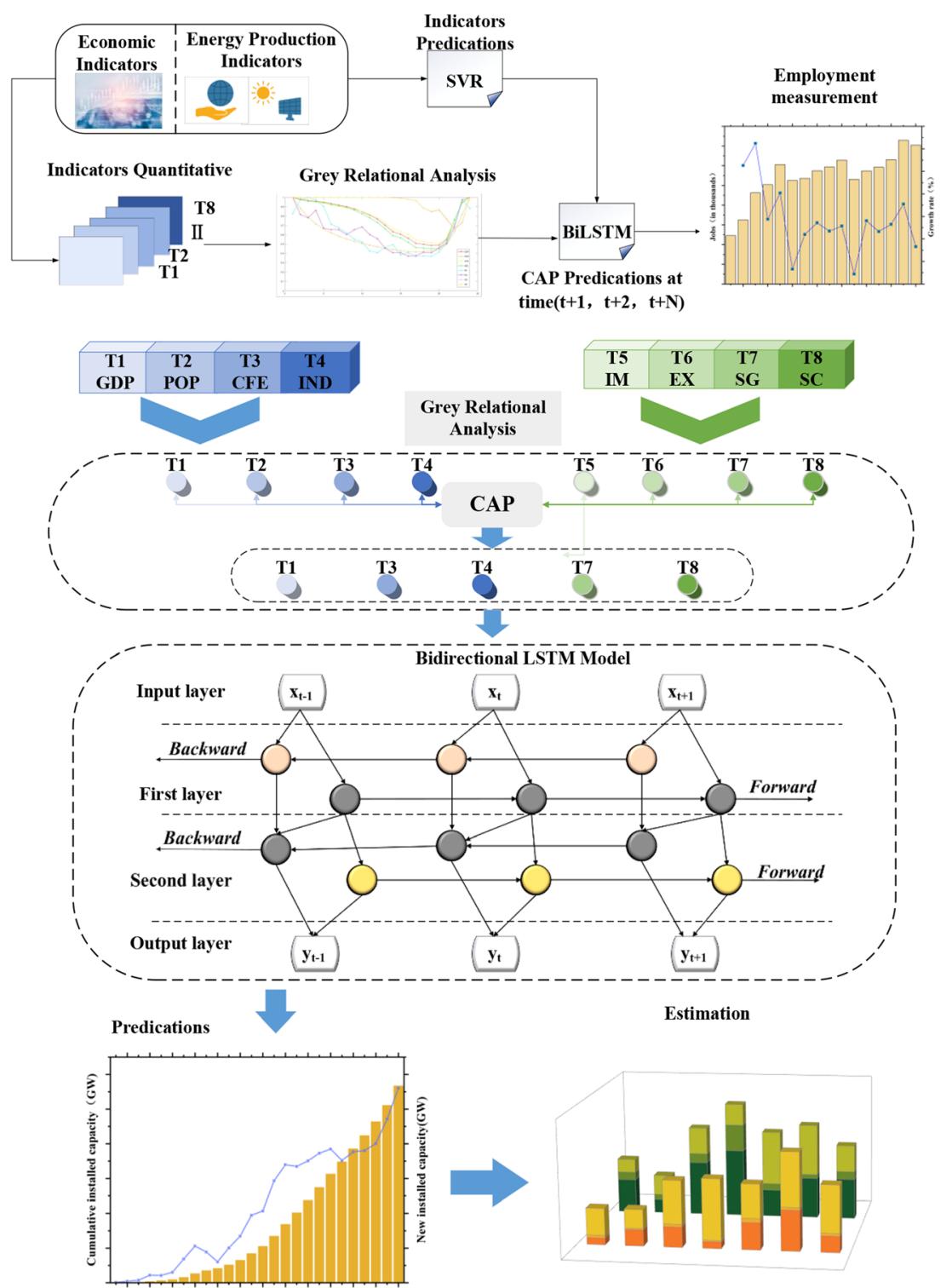

sequence at $k$ time. Finally, the correlation degree of the reference sequence is calculated according to formula $5, \rho_{i}$ indicates the overall closeness between the comparison sequence and the reference sequence.

$\xi i(k)=\frac{\min _{i, k}|x 0(k)-x i(k)|+\varepsilon \max _{i, k}|x 0(k)-x i(k)|}{|x 0(k)-x i(k)|+\varepsilon \max _{i, k}|x 0(k)-x i(k)|}$

$\rho i=\sum_{k=1}^{m} \frac{1}{m} \xi i(k)$

\section{Employment factors}

One of the main advantages of EF method is that it can be modified for specific environment, and can also be applied to a series of energy scenarios. It is simpler and more effective in predicting direct employment related to energy production, storage, and transmission. Figure 4 outlines the method for estimating renewable energy job creation during the energy transition period from 2020 to 2035. As the fuel supply does not involve solar energy, this paper estimates that the number of solar PV industry employment in 2020-2035 is the sum of manufacturing, construction and installation, operation, and maintenance. Manufacturing jobs include equipment and component manufacturing jobs of power plant projects; construction and installation jobs include all jobs related to installation construction and installation; operation and maintenance jobs include all jobs related to operation and maintenance in the whole cycle of equipment operation. 


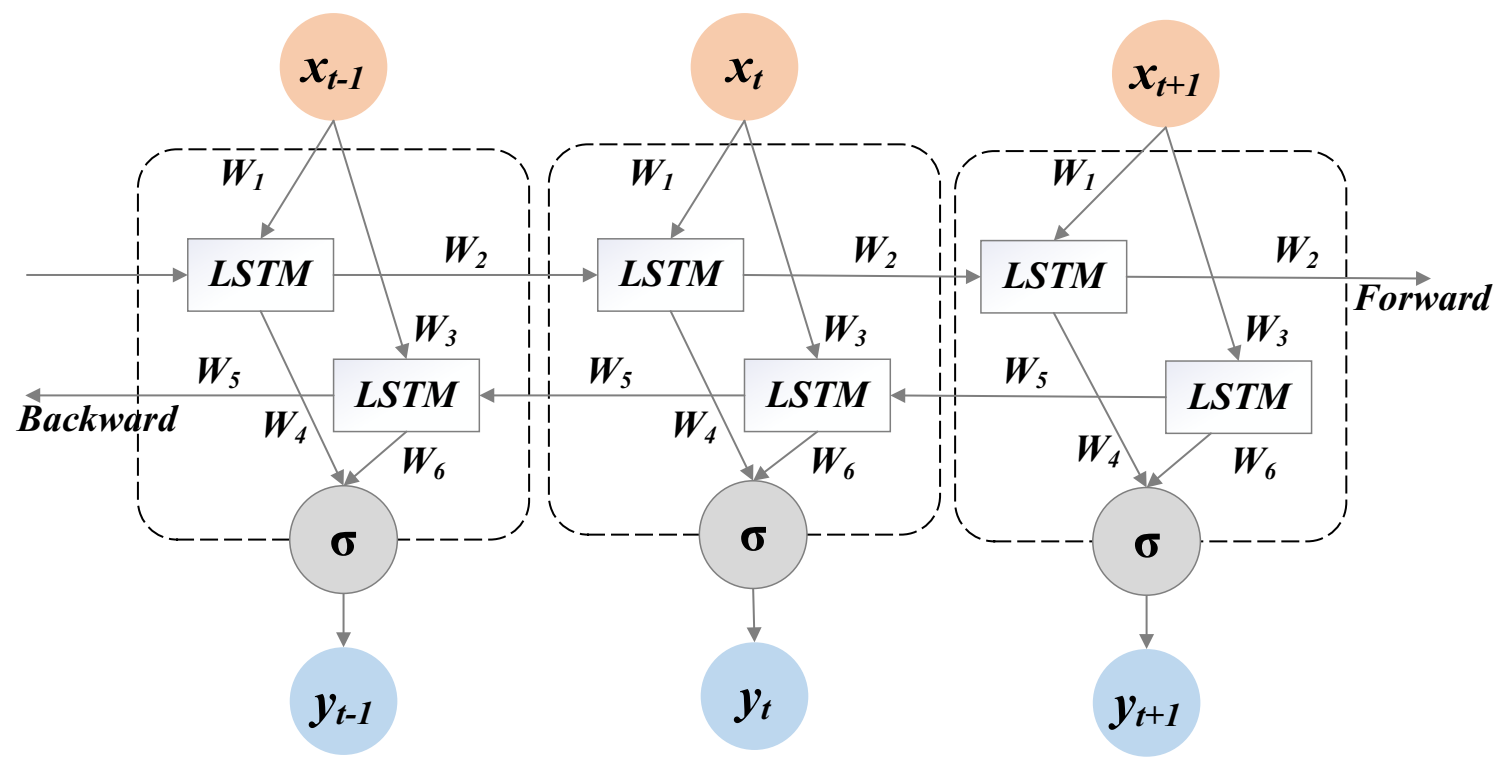

Fig. 3 Bidirectional long short-term memory (BiLSTM) model structure

Among them, the employment factor refers to the number of jobs provided by unit installed capacity, and the coefficient changes according to the actual demand of different jobs, separated into manufacturing, construction and installation, operation and maintenance, and decommissioning. The employment factors of PV industry used in this study comes from Rutovitz et al. (2015) and solar power Europe. Decline factor based on capex means that with the maturity and intelligence level of renewable energy technology, the scale effect gradually appears, and the employment opportunities that can be created gradually decrease; the decline factor based on capex of PV industry used in this study comes from Ram et al. (2017); Regional employment multiplier refers to the differences in labor productivity and labor cost caused by different regional economic development. It can effectively and reasonably quantify the employment ability of different regions. This study uses the regional employment coefficient based on labor productivity factors which are derived from International Labour Organization and International Monetary Fund World Economic Outlook.

\section{Data}

In this paper, the influence of macroeconomic indicators on the power market is fully considered, and the factors affecting

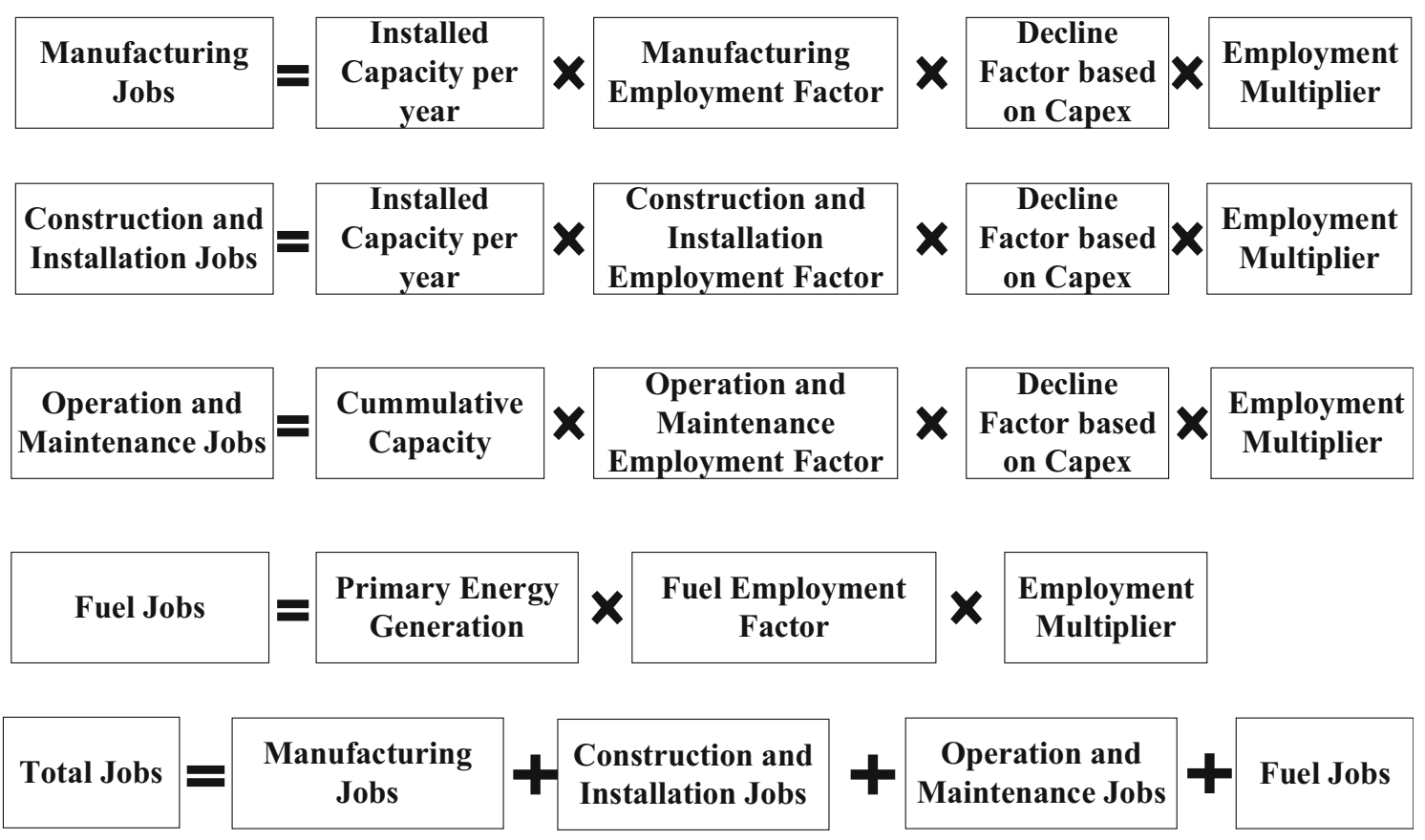

Fig. 4 Method for estimation of renewable energy jobs 
the installed capacity of solar PV are determined as follows through the review of relevant literature.

\section{Gross domestic product (GDP) and residential consumption expenditure (HCE)}

Economic growth is the main driver of accumulated installed capacity. The development of electric power consumption depends on the continuous development of industrialization, commercialization, and informatization. Moreover, the increase in installed capacity is dependent on state and private investment, which depends on rapid economic development.

\section{Population (POP)}

The population is a fundamental aspect of the social economy. It will directly affect the demand for electricity in a region and thus the amount of installed capacity.

\section{Industrial value added (IND)}

In a highly industrialized society, materials and products are produced in a mechanized manner, and the industrial sector uses high amounts of electricity, which increases the demand for installed capacity. This paper chooses the industrial added value as the index representing the development of industrialization.

\section{Solar energy generation and solar energy consumption (SG and SC)}

These energy production indicators are most closely related to solar installed capacity. The demand for the electricity market directly drives the development of the power equipment market.

\section{Import and export of electricity (IM and EX)}

The import and export of electricity reflect a country's dependence on electricity. Dependence on energy imports has encouraged countries to adopt incentives to develop domestic electricity markets and to increase government and private investment in power generation markets.

The data are shown in Fig 5, in which the data of China's installed solar PV capacity, solar power generation, and solar energy consumption are derived from the BP Statistical Yearbook. Macroeconomic indicators include GDP, population, and household consumption expenditure; industrial added value comes from the World Bank; electric power export and electric power import come from EIA (Energy Information Administration). There are 24 sets of data in this paper. From 1996 to 2019, 19 sets of data from 1996 to 2014

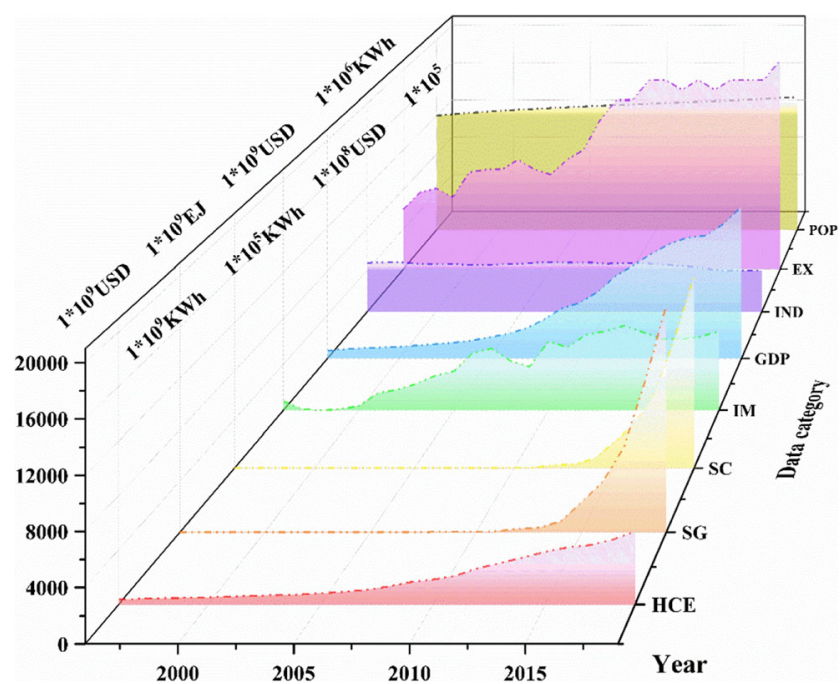

Fig. 5 Original Data

are selected as training samples, and 5 sets of data from 2015 to 2019 are selected as test samples.

\section{Empirical study}

\section{Data pre-processing}

In this paper, the grey correlation analysis is used to calculate the correlation degree between the solar installed capacity data and various influencing factors from 1996 to 2019. The calculation results are shown in Table 1. Excluding the indicators below 0.7, the main indicators affecting China's solar installed capacity are GDP, final consumer expenditure, industrial added value, solar power generation, and solar energy consumption.

\section{Model accuracy}

To verify the validity and accuracy of the proposed forecast model for solar installed capacity, three error analysis

Table 1 Grey relation degree between influencing indicators and China's PV installed capacity

\begin{tabular}{ll}
\hline Influencing factor & Grey relation degree \\
\hline GDP & 0.7763 \\
Population & 0.5912 \\
Household consumption expenditure & 0.784 \\
Industrial added value & 0.7568 \\
Electricity import & 0.6225 \\
Electricity export & 0.6242 \\
Solar generation & 0.9446 \\
Solar consumption & 0.9456 \\
\hline
\end{tabular}


methods, namely absolute percentage error (APE), mean absolute error (MAE), root mean square error (RMSE), and mean absolute percentage error (MAPE), were selected in this paper to evaluate the model results, as shown in Formulas 6-8.

$$
\begin{aligned}
& \mathrm{APE}=\frac{\left|\widehat{y}_{i}-y_{i}\right|}{y_{i}} * 100 \% \\
& \mathrm{MAE}=\frac{1}{n} \sum_{i=1}^{n}\left|\widehat{y}_{i}-y_{i}\right| \\
& \mathrm{RMSE}=\sqrt{\frac{1}{n} \sum_{i=1}^{n}\left(\widehat{y}_{i}-y_{i}\right)^{2}} \\
& \mathrm{MAPE}=\frac{100 \%}{n} \sum_{i=1}^{n}\left|\frac{\widehat{y}_{i}-y_{i}}{y_{i}}\right|
\end{aligned}
$$

Where $\hat{y}=\left\{\hat{y}_{1}, \hat{y}_{2}, \cdots, \widehat{y}_{n}\right\}$ is the predicted value, $y=\left\{y_{1}\right.$, $\left.y_{2}, \cdots, y_{n}\right\}$ is the true value, $n$ is the number of index variables. Zeng et al. (2017b) provide the model evaluation criteria for MAPE of previous studies listed in Table 2. Since the index APE is independent of the order of magnitude, it has been widely adopted to assess the precision of the prediction models. Lower indicator values represent more satisfactory forecasting ability and higher precision.

To evaluate and analyze the prediction performance of the GRA-BiLSTM combination model, this paper adopts multiple linear regression (MLR), support vector regression (SVR), gated recurrent unit (GRU), and long- and short-time memory network (LSTM) as the comparison models based on the same input time series. Using the same proportion of training set to test the learning performance of each model and comparing the prediction performance of nine models based on the above prediction model evaluation index, the BiLSTM neural network contains four parameters that affect the prediction accuracy of the model, including the number of learning rate, the time step of each layer, the number of hidden_layer of each layer, and the number of training epoch. In the training process of the model, the setting of a single parameter is different, but other parameters are the same, so as to find the best prediction model. Each parameter setting in the proposed model is shown

Table 2 Typical MAPE values for accuracy evaluation
Table 3 Proposed parameter setting for the BiLSTM neural network

\begin{tabular}{llllll}
\hline Algorithms & Time step & Hidden_layer & Batch size & Lr & Epoch \\
\hline GRA-BiLSTM & 2 & 32 & 2 & 0.001 & 10000
\end{tabular}

in Table 3. The APE values of ten prediction models from 1996 to 2019 are shown in Table 4. The calculation results of performance and evaluation indexes are shown in Table 5.

The MAE, MAPE, and RMSE values of the GRABiLSTM model are 6.571, 5.995, and 7.666, respectively, which are lower than those of other models. Therefore, the GRA-BiLSTM model has good applicability for predicting the installed solar capacity. The possible reason is that considering the data characteristics of output indicators, statistical methods such as multiple linear regression are not applicable to nonlinear data. Machine learning and deep learning predictive models can fully learn the correlation between input and output variables just like human neural networks. In particular, the deep learning model can have a more comprehensive understanding of the trend of time series data and has a higher prediction accuracy, while the SVR model considers more local optimization and has a slower convergence speed. It is suitable for predicting the installed solar capacity of China's solar PV power generation. Figure 6 shows the prediction results of the GRA-BiLSTM model and the other nine models, directly reflecting the degree of fit between the predicted values of the nine models and the actual values. The results show that all the nine prediction models can achieve reasonable prediction, and the screening of input indexes through grey-relational-analysis plays an obvious role in improving the accuracy of prediction results.

\section{Mean impact value}

In order to test the validity and stability of the model, this paper further determines the contribution of each input index to the experimental results through MIV analysis. MIV is a common method to determine the relative importance of each input index in artificial neural network. MIV analysis method can measure the influence of input variables on output variables in the multi-factor prediction model (Xu et al. 2019; Feng et al. 2021). A positive value of MIV indicates a variable directly related to the output, while a negative value indicates the opposite relationship. A value close to zero indicates that the input variable is not related to the output variable. Increase and decrease each input indicator by $10 \%$, and get new data set $X_{i}^{(1)}$ and $X_{i}^{(2)}$, it is shown in Formula 9-10, where $n$ represents the number of samples in the training set; $p$ represents the number of input variables. Then the data sets $X_{i}^{(1)}$ and $X_{i}^{(2)}$ are put into the BiLSTM model for training, get the output sets 
Table 4 The APE (\%) values of all prediction models from 1996 to 2019

\begin{tabular}{|c|c|c|c|c|c|c|c|c|c|c|}
\hline Year & MLR & SVR & GRU & LSTM & BiLSTM & $\begin{array}{l}\text { GRA- } \\
\text { MLR }\end{array}$ & $\begin{array}{l}\text { GRA- } \\
\text { SVR }\end{array}$ & $\begin{array}{l}\text { GRA- } \\
\text { GRU }\end{array}$ & $\begin{array}{l}\text { GRA- } \\
\text { LSTM }\end{array}$ & $\begin{array}{l}\text { GRA- } \\
\text { BiLSTM }\end{array}$ \\
\hline 1996 & 70.00 & 130.00 & 140.00 & 120.00 & 50.00 & 20.00 & 30.00 & 210.00 & 220.00 & 9.00 \\
\hline 1997 & 56.00 & 12.00 & 56.00 & 28.00 & 40.00 & 160.00 & 28.00 & 48.00 & 80.00 & 16.00 \\
\hline 1998 & 56.00 & 14.00 & 46.00 & 34.00 & 10.00 & 50.00 & 24.00 & 24.00 & 30.00 & 10.00 \\
\hline 1999 & 115.00 & 8.00 & 10.00 & 25.00 & 100.00 & 75.00 & 13.00 & 32.00 & 20.00 & 20.00 \\
\hline 2000 & 13.96 & 11.28 & 3.22 & 6.03 & 29.80 & 10.68 & 9.49 & 3.04 & 29.83 & 2.95 \\
\hline 2001 & 37.03 & 5.47 & 20.46 & 11.42 & 6.18 & 25.99 & 11.26 & 15.47 & 2.63 & 3.55 \\
\hline 2002 & 6.32 & 8.08 & 4.90 & 0.00 & 17.69 & 9.85 & 5.61 & 15.80 & 7.08 & 10.51 \\
\hline 2003 & 8.56 & 9.91 & 31.08 & 34.53 & 24.47 & 10.96 & 5.26 & 23.57 & 1.95 & 15.02 \\
\hline 2004 & 13.71 & 7.44 & 21.02 & 3.52 & 13.05 & 20.50 & 11.75 & 7.83 & 7.91 & 3.92 \\
\hline 2005 & 19.62 & 8.50 & 12.11 & 21.46 & 4.46 & 22.03 & 12.54 & 26.56 & 1.77 & 7.79 \\
\hline 2006 & 10.42 & 6.05 & 10.61 & 16.73 & 2.18 & 14.36 & 8.80 & 8.55 & 19.85 & 6.24 \\
\hline 2007 & 9.55 & 5.03 & 8.54 & 16.08 & 6.03 & 11.06 & 2.01 & 11.56 & 10.05 & 5.03 \\
\hline 2008 & 66.40 & 10.28 & 4.74 & 9.09 & 15.81 & 28.06 & 19.76 & 7.11 & 27.11 & 3.95 \\
\hline 2009 & 23.00 & 19.02 & 0.34 & 9.14 & 24.11 & 14.25 & 16.49 & 7.38 & 28.93 & 12.05 \\
\hline 2010 & 78.12 & 57.57 & 44.45 & 6.30 & 4.90 & 65.39 & 29.18 & 10.78 & 0.80 & 20.55 \\
\hline 2011 & 20.52 & 14.09 & 11.27 & 10.15 & 4.48 & 10.23 & 9.58 & 6.83 & 18.39 & 12.87 \\
\hline 2012 & 40.20 & 11.78 & 10.88 & 11.83 & 13.77 & 25.47 & 8.95 & 7.79 & 16.44 & 7.46 \\
\hline 2013 & 19.42 & 12.78 & 8.14 & 8.76 & 13.78 & 13.73 & 8.16 & 3.94 & 4.89 & 7.88 \\
\hline 2014 & 30.17 & 17.21 & 4.47 & 6.47 & 3.82 & 24.80 & 10.45 & 3.65 & 3.46 & 3.87 \\
\hline 2015 & 24.22 & 16.76 & 14.12 & 29.63 & 8.07 & 16.76 & 17.33 & 24.67 & 25.65 & 6.34 \\
\hline 2016 & 38.31 & 14.78 & 24.46 & 6.79 & 2.92 & 27.63 & 19.91 & 3.50 & 5.82 & 6.25 \\
\hline 2017 & 23.35 & 9.59 & 15.71 & 2.56 & 18.16 & 17.24 & 19.53 & 19.66 & 11.26 & 10.28 \\
\hline 2018 & 21.24 & 13.26 & 9.28 & 14.11 & 5.33 & 18.39 & 9.84 & 8.74 & 6.70 & 2.73 \\
\hline 2019 & 27.99 & 13.39 & 13.40 & 7.72 & 9.23 & 28.56 & 18.25 & 9.97 & 4.78 & 4.39 \\
\hline
\end{tabular}

$Y_{i}^{(1)}=\left[y_{i 1}^{(1)}, y_{i 2}^{(1)}, \cdots, y_{i m}^{(1)}\right]$ and $Y_{i}^{(2)}=\left[y_{i 1}^{(2)}, y_{i 2}^{(2)}, \cdots, y_{i m}^{(2)}\right]$. According to $Y_{i}^{(1)}$ and $Y_{i}^{(2)}$, the average influence value and contribution degree of each index is calculated. The formula is shown in 9-12.

Table 5 Comparison of prediction performances using deep learning models

\begin{tabular}{llll}
\hline Algorithms & MAE & MAPE (\%) & RMSE \\
\hline MLR & 33.131 & 27.024 & 36.406 \\
SVR & 20.668 & 16.973 & 23.038 \\
GRU & 17.905 & 15.393 & 19.209 \\
LSTM & 12.421 & 12.158 & 14.615 \\
BiLSTM & 11.568 & 8.741 & 14.341 \\
GRA-MLR & 28.418 & 21.715 & 32.971 \\
GRA-SVR & 16.418 & 13.556 & 19.109 \\
GRA-GRU & 14.997 & 13.307 & 16.961 \\
GRA-LSTM & 10.397 & 10.841 & 10.923 \\
GRA-BiLSTM & 6.571 & 5.995 & 7.666 \\
\hline
\end{tabular}

$$
X_{i}^{(1)}=\left[\begin{array}{cccc}
X_{11} & X_{12} & \ldots & X_{1 n} \\
X_{21} & X_{22} & \ldots & X_{2 n} \\
\vdots & \vdots & \ldots & \vdots \\
X_{i 1}(1+10 \%) & X_{i 2}(1+10 \%) & \ldots & X_{i n}(1+10 \%) \\
\vdots & \vdots & \ldots & \vdots \\
X_{p 1} & X_{p 2} & \ldots & X_{p n}
\end{array}\right]
$$

$$
X_{i}^{(2)}=\left[\begin{array}{cclc}
X_{11} & X_{12} & \ldots & X_{1 n} \\
X_{21} & X_{22} & \ldots & X_{2 n} \\
\vdots & \vdots & \ldots & \vdots \\
X_{i 1}(1-10 \%) & X_{i 2}(1-10 \%) & \ldots & X_{\text {in }}(1-10 \%) \\
\vdots & \vdots & \ldots & \vdots \\
X_{p 1} & X_{p 2} & \ldots & X_{p n}
\end{array}\right]
$$

$$
M I V i=\sum_{j=1}^{m} \frac{y_{i j}^{(1)}-y_{i j}^{(2)}}{m}
$$

$C i=\frac{M I V i}{\sum_{i=1}^{p}|M I V i|} 100 \%$ 
Fig. 6 Prediction performance of GRA-BiLSTM model and other models
The results of MIV and the contribution of each index are shown in Table 6. According to the calculation results, SG and SC have a significant impact on the prediction of solar installed capacity. With the continuous reduction of the production cost of solar panels and the increase of the demand for

Table 6 Input variables, mean MIV, and contribution rate

\begin{tabular}{llllll}
\hline Variables & GDP & CFE & IND & SG & SC \\
\hline MIV & 0.89 & 0.77 & 0.71 & 1.35 & 1.39 \\
Contribution & $17.42 \%$ & $15.07 \%$ & $13.89 \%$ & $26.42 \%$ & $27.20 \%$ \\
\hline
\end{tabular}

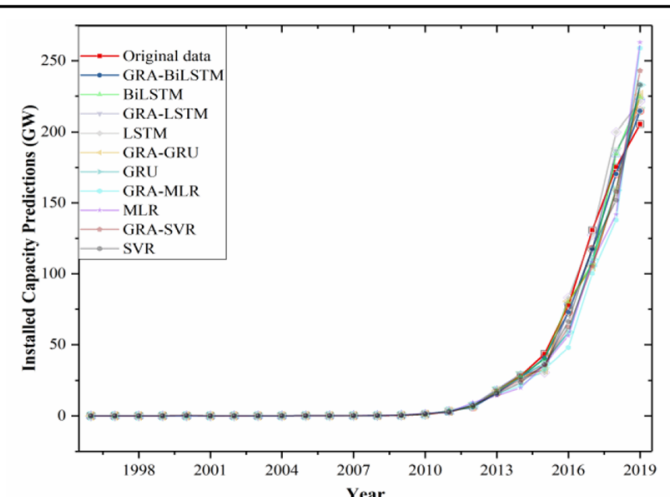

Year
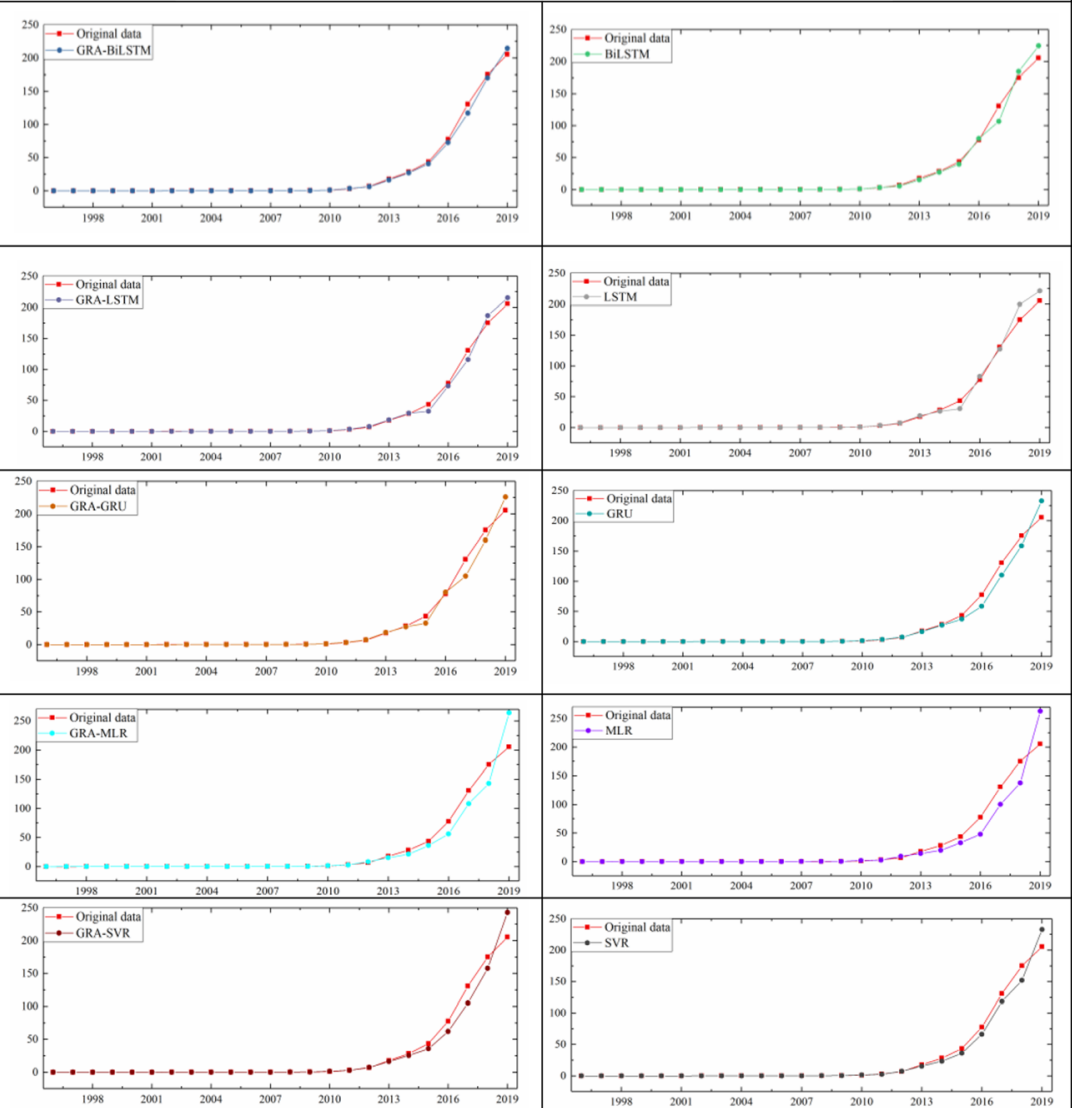

renewable energy, the growth rate of the demand and consumption of solar energy is gradually accelerating. The installation and construction of PV generation equipment in areas with abundant solar energy is more promising than the existing coal or natural gas power generation. GDP has a high contribution to the prediction of solar installed capacity. The rapid growth of national economy provides a guarantee basis for the installation of photovoltaic installed capacity equipment, and promotes the continuous upgrading of photovoltaic power generation technology and the wide application of distributed photovoltaic. While IND and CFE have a low contribution, electricity demand mainly comes from residential electricity and industrial added value. With 
the continuous expansion of electricity demand in the whole society, renewable energy will become the main source of power generation. The growth of residential consumption expenditure and industrial added value will further promote the expansion of photovoltaic installed capacity.

\section{Discussion}

\section{Annual new solar PV installed capacity forecast}

On the basis of literature research, fully considering the data characteristics of the input data and the applicability of the SVR model for single-factor prediction. This paper uses the SVR model to predict the input indicators from 2020 to 2035. Taking the above indicators as the input data of the BiLSTM model prediction, China's solar installed capacity in 2020 2035 is obtained through model learning, and the results are shown in Fig 7.

As Fig 7 presented, since China's cumulative installed solar PV capacity was relatively small before 2010, this study divided the changes of new installed solar PV capacity from 2010 to 2035 into three stages for analysis:

The first stage is from 2010 to 2019. China's solar PV installed capacity increases geometrically, accumulative total installed capacity of $1.02 \mathrm{GW}$ in 2010 increased to 130.82 $\mathrm{GW}$ in 2017. However, the newly added solar PV installed capacity decreases year by year in 2017-2019. The reason for this phenomenon is that in the early stage of the development of the photovoltaic market, the government strongly subsidized the production, installation, and power generation of the photovoltaic industry.
Secondly, China adjusted the photovoltaic subsidy policy in 2018, proposing that the PV industry should maintain a reasonable scale and pace of development, reducing the intensity of subsidies to the PV industry, and the era of "no subsidy for photovoltaic" is approaching. A wide range of PV subsidy policies resulted in subsidy gaps, project stagnation, and other problems, which had a great impact on domestic demand; the overall growth of PV new installed capacity slowed down.

The second stage is from 2020 to 2025. Based on the prediction of SVR and BiLSTM model, China's new solar PV installed capacity will grow rapidly, from $50.37 \mathrm{GW}$ in 2020 to $146.76 \mathrm{GW}$ in 2025 . After 2020 , the state will issue a series of policies to effectively undertake the "solar PV $531 \mathrm{New}$ Deal," encourage and support the development of distributed solar PV; and the development cost of new energy such as wind energy and solar energy will drop rapidly, which makes it possible to build an energy system with clean energy as the main body and solve the climate and environmental crisis. As the situation of COVID-19 epidemic prevention and control in China improves, the PV industry returns to work and production faster; domestic and foreign market demand and projects accelerate; the PV industry will gradually step into the era of "affordable Internet access."

The third stage is from 2025 to 2035 . According to the forecast results of the model, the overall development of China's solar PV industry will show steady growth. By 2035, China's cumulative installed solar PV capacity will reach $2833 \mathrm{GW}$. With the continuous progress of material technology and process technology, the driving force of the solar PV industry has shifted from the original subsidies to the endogenous drive of scientific and technological research and development, and the solar PV market has stepped into the era
Fig. 7 Phase analysis of China's installed solar capacity in 20102035

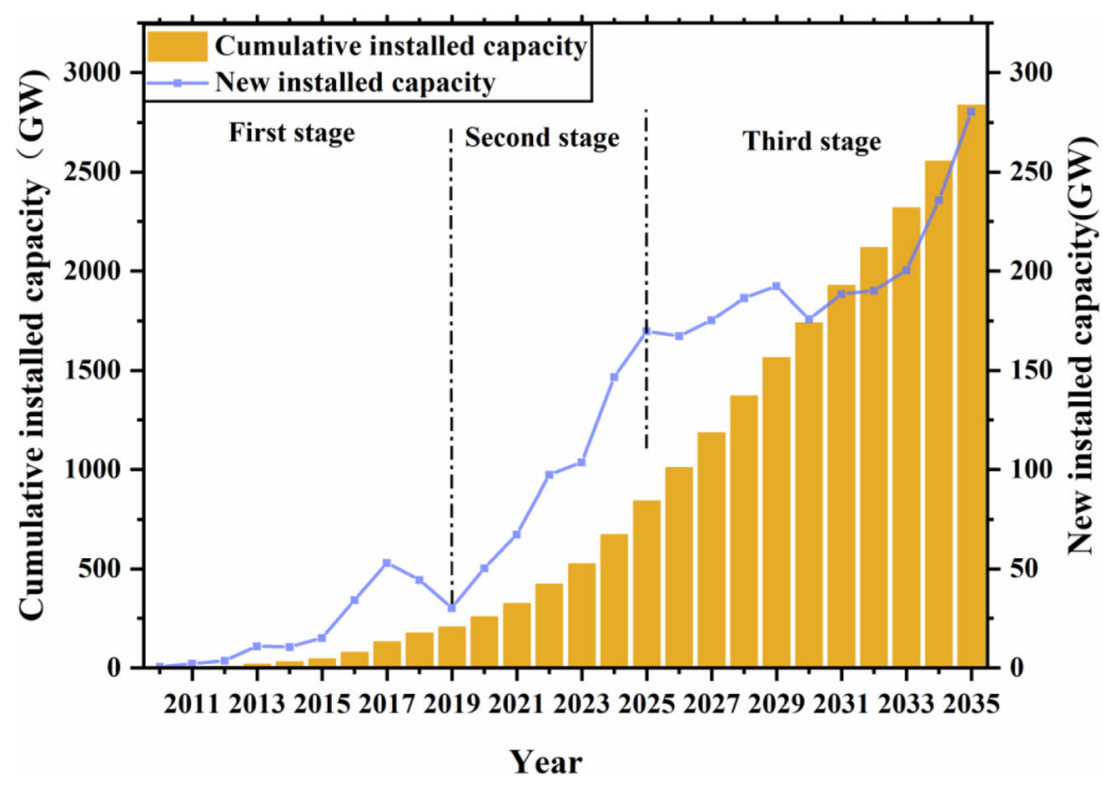

Year 
of "affordable Internet access." At the same time, to step into the era of "renewable energy" and realize the goal that renewable energy generation accounts for more than $50 \%$ of the global electricity supply, China's installed solar PV capacity will enter the stage of scale effect, and more investment in solar PV industry will drive the sustained growth of GDP. During the energy transformation period, the photovoltaic industry is bound to follow the path from "affordable Internet access" to "low-cost Internet access" and then to clean substitution, laying the foundation for the long-term goal of forming an energy system based on renewable energy in China by 2050.

As the public's attitude towards expanding the scale of the solar PV industry will be eased, economic growth and electricity demand will continue to slow down, so China's energy transformation to green energy will be impeded. Coal-fired power generation is still in the leading position, which makes the government lack full and reasonable understanding role of the solar PV industry in creating employment and improving employment structure. This paper forecasts the number of jobs created by China's solar PV industry from 2020 to 2035 by using the EF method, which includes three types: manufacturing, construction and installation, and operation and maintenance. As can be seen from Figure 8, with the reduction of renewable energy costs and the continuous growth of the solar PV installed capacity, the employment of the solar PV industry in 2020-2035 shows a gradual upward trend. The strong growth of solar PV industry makes the employment of solar PV industry reach 3.52 million in 2035, an increase of $187 \%$

Table 7 Jobs and Jobs/MW ratio in China's solar PV industry, 20202035

\begin{tabular}{llll}
\hline Year & Installed capacity(MW) & Jobs & $\begin{array}{l}\text { Jobs/ } \\
\text { MW }\end{array}$ \\
\hline 2020 & 255,858 & $1,225,178$ & 4.788 \\
2021 & 323,240 & $1,625,173$ & 5.027 \\
2022 & 420,622 & $2,314,666$ & 5.502 \\
2023 & 524,217 & $2,518,545$ & 4.804 \\
2024 & 670,979 & $3,032,495$ & 4.519 \\
2025 & 840,763 & $2,627,868$ & 3.125 \\
2026 & $1,008,117$ & $2,679,943$ & 2.658 \\
2027 & $1,183,499$ & $2,872,006$ & 2.426 \\
2028 & $1,369,893$ & $2,972,628$ & 2.169 \\
2029 & $1,562,307$ & $3,142,715$ & 2.011 \\
2030 & $1,738,169$ & $2,654,615$ & 1.527 \\
2031 & $1,926,528$ & $2,868,705$ & 1.489 \\
2032 & $2,116,664$ & $2,963,261$ & 1.399 \\
2033 & $2,317,018$ & $3,156,499$ & 1.362 \\
2034 & $2,552,697$ & $3,645,193$ & 1.427 \\
2035 & $2,833,058$ & $3,521,850$ & 1.243 \\
\hline
\end{tabular}

compared with 2020. In 2020-2024, the growth rate is large, but after 2024, the growth rate gradually slows down. The results show that, with the rapid expansion of the solar PV market in the future, the employment prospect of solar PV industry can be predicted. Meanwhile, with the help of the solar PV installed capacity and the number of employees from 2020 to 2035 predicted above, the employment megawatt ratio of the solar PV industry can be obtained, as shown in Table 7. From 2020 to 2035, the employment megawatt ratio of the solar PV industry shows a downward trend year by year. The reason for this result is that due to the continuous improvement of scale economy and technology development level of solar PV industry, mechanization and automation are replacing manual labor.

With economic stagnation and high unemployment in many regions under the influence of COVID-19 in 2020, job creation is a major priority when designing policies. In the report issued by the Chinese government in 2021, it was pointed out that, when formulating macro policies, persisting in giving top priority to employment and expanding employment channels will create more jobs to promote steady and sound economic growth. As the Chinese government continues to deploy and promote the development of renewable energy, it will gradually maximize the benefits of renewable energy development and make it a powerful "engine" to boost economic development and alleviate employment problems.

As can be seen from Fig 9 and Table 8, with the continuous expansion of the solar PV market, the construction and installation of solar PV installed capacity has created a large number of employment opportunities, which will account for $54 \%$ of the total employment opportunities in 2035. The proportion of manufacturing jobs is relatively high in the initial stage before 2025, and it will stabilize after this stage until 2035. The development of solar PVrelated manufacturing industry will create a number of jobs with high technical requirements and service level, covering design materials, equipment manufacturing, power, and automatic control, and other fields.

During the transition period, the share of operation and maintenance work increased from $14 \%$ of the total jobs in 2020 to $27 \%$ of the total jobs in 2035 . With the continuous growth of solar PV installed capacity, the operation and maintenance of power facilities has become a crucial part. In the current situation of the normalization of the epidemic, in order to effectively reduce the impact of the epidemic on poor outdoor workers, different regions can provide public welfare jobs according to the actual needs of local photovoltaic industry development, and promote poor people's local and nearby employment. The poor households are encouraged to obtain labor income through their efforts, and actively participate in photovoltaic operation and maintenance to ensure the effective supply of labor. 
Fig. 8 Annual employment and growth rate of photovoltaic industry in 2020-2035

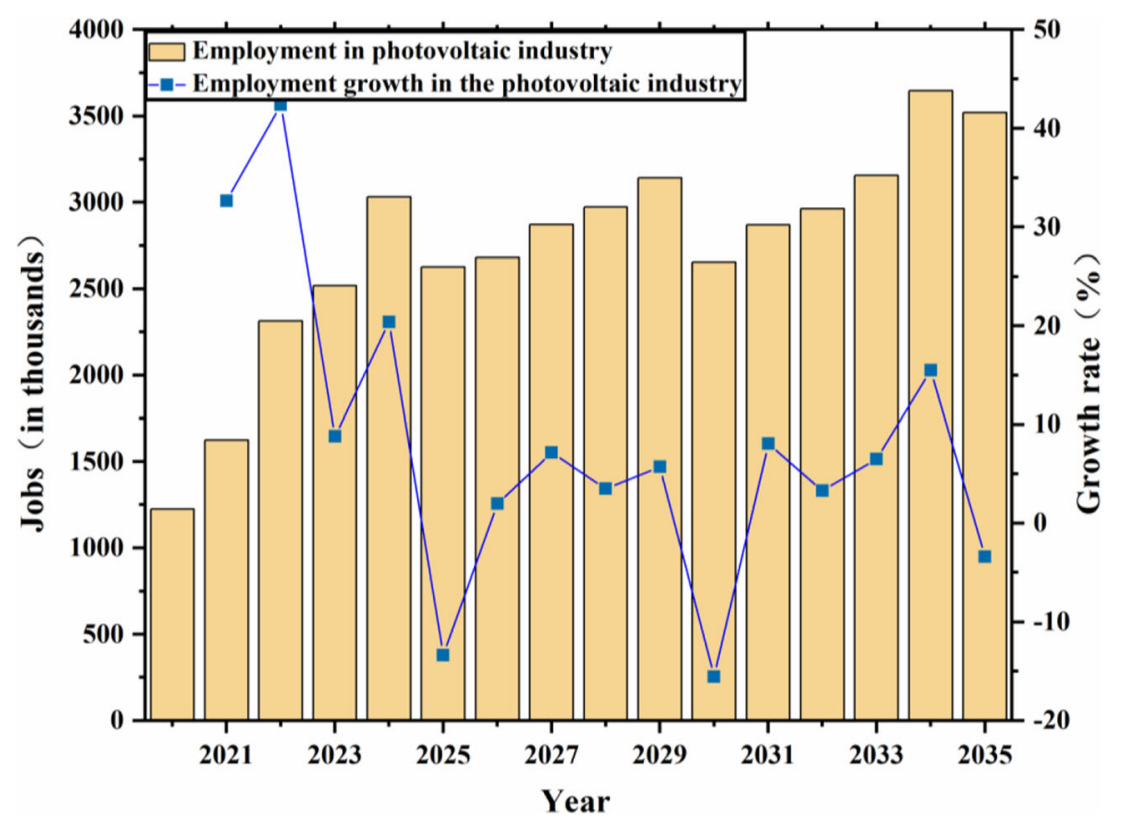

\section{Conclusions and policy implications}

\section{Conclusions}

This study predicts and analyzes the development prospects of China's solar PV industry during the energy transition period. The positive role of photovoltaic industry in broadening employment channels and alleviating employment pressure under the normalization of epidemic situation is further discussed. (1) This paper puts forward a forecasting model of China's solar PV installed capacity based on GRA-BiLSTM. By optimizing and adjusting the parameters of the model, the prediction performance of the model is evaluated. The MAPE value of GRA-BiLSTM is 5.995, which indicates that the GRA-BiLSTM method is more suitable for multi-factor solar PV installed capacity forecasting than the benchmark models GRU and LSTM. At the same time, MIV analysis was used to evaluate the impact of each input index on the output index. Solar energy consumption and solar power generation have the greatest impact, with an average contribution rate of $26.42 \%$ and $27.20 \%$. (2) The BiLSTM model is used to forecast the

Table 8 Jobs and Jobs/MW ratio in China's solar PV industry in 2035

\begin{tabular}{lll}
\hline & Jobs & $\begin{array}{l}\text { Jobs/ } \\
\text { MW }\end{array}$ \\
\hline Manufacturing & 70,0731 & 0.247 \\
Operation and maintenance & 902,712 & 0.318 \\
Construction and installation & $1,918,405$ & 0.677 \\
Total & $3,521,850$ & \\
\hline
\end{tabular}

installed solar PV capacity in China from 2020 to 2035. Forecast results show that China's solar PV installed capacity will continue to grow in the future, and China's solar PV installed capacity will reach $2833 \mathrm{GW}$ in 2035 . Meanwhile, combined with the historical data of installed capacity, this paper discusses the stage characteristics and reasons for China's installed capacity. The results show that the solar PV installed capacity shows an exponential growth trend in the early stage, mainly because the solar PV subsidy policy plays a crucial role in the early development of the solar PV market, but with the scale and intensification of the PV industry and the decline of subsidies, the growth rate of solar PV installed capacity will gradually slow down. (3) This paper estimates the future solar PV market by using the predicted value of installed capacity. Before 2025, the number of jobs in different industries will increase rapidly, but with the continuous improvement of scale economy and technology development level of solar PV industry, the growth rate of jobs will slow down. In 2035, the number of new jobs in solar PV industry will reach 3.5218 million, an increase of about $187 \%$ compared with 2020 . China's solar PV industry is in good shape, and it is in the stage of expansion, constantly attracting labor to join the solar PV industry. These results are of practical value to the decisionmaking of power enterprises and the formulation of energy planning and employment policy of the government.

Due to the difficulty in obtaining some index data and the inconsistency of some data in scale, the PV installed capacity prediction model has limitations in the selection of input index. The next step of the study will consider the photovoltaic support policies and technological research can be used as the input index of the same model. 
Fig. 9 Various jobs in China's photovoltaic industry in 2020 2035

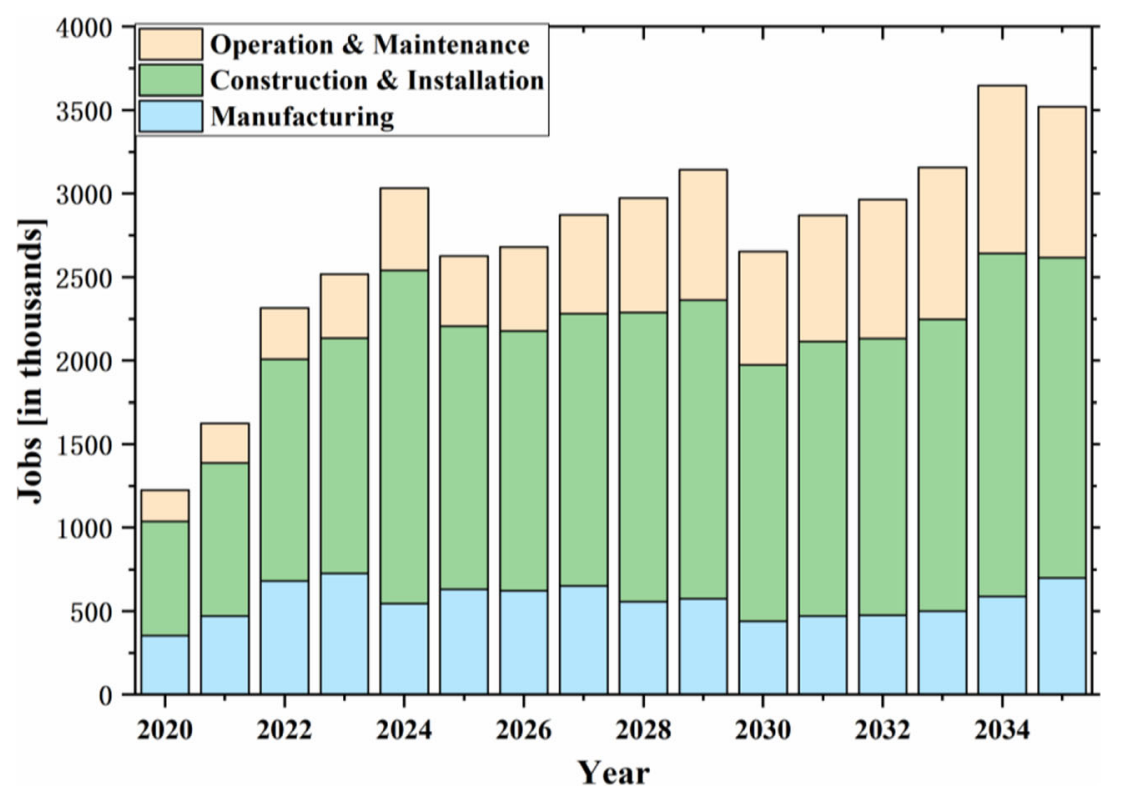

\section{Policy implications}

On the one hand, according to the prediction of this study, China's photovoltaic installed capacity will enter the stage of scale effect, and more photovoltaic industry investment will drive the sustained growth of GDP. On the road of energy transformation and transformation, photovoltaic power generation is bound to follow the path from "affordable access to the Internet" to "low price access to the Internet," and then to clean replacement, which lays the foundation for the long-term goal of China to form an energy system dominated by renewable energy in 2050 . Chinese governments at all levels should formulate or adjust the equipment installation and employment support policies of relevant photovoltaic industry according to the actual situation of local photovoltaic industry development, so as to ensure the healthy and rapid development of China's photovoltaic industry. As most of China's installed solar energy capacity is distributed in Xinjiang, Inner Mongolia, Qinghai, Gansu, and other areas with sufficient sunshine but slow economic development, the development of solar PV industry can not only help the rapid development of the local economy, but also effectively alleviate the employment pressure of local labor market.

On the other hand, with the innovation of industrial technology, the reduction of cost, and the enhancement of competitiveness, many employment opportunities are created with the actual needs of different types of jobs, and more and more employment opportunities will be available for innovative talents and senior managers. But at present, there are few colleges and universities offering solar PV specialty in China. Most of the existing technical personnel are from various vocational colleges. There is a lack of corresponding research talents in the fields of design materials, equipment manufacturing, electric power, and automatic control. As a result, many solar PV enterprises have to employ graduates majoring in electronics, materials and so on, resulting in problems such as professional mismatch. Continuous technological progress is the biggest thrust to reduce the cost of solar PV power generation, and the rapid reduction of the cost of solar PV power generation is the firm cornerstone to achieve a high proportion of solar PV installed capacity deployment. Therefore, we need to make great efforts in professional training and education in colleges and universities to reserve corresponding high-end talents for the solar PV industry. It is suggested that all kinds of colleges and universities should set up relevant solar PV majors, carry out systematic teaching, and strengthen the cooperation between solar PV enterprises and universities and scientific research institutions, which is of positive significance to build the core competitiveness of enterprises and enhance the scientific research strength of colleges and universities.

Author contribution Bingchun Liu: Conceptualization, Methodology. Chengyuan Song: Data curation, Writing-Original draft preparation, Writing-Reviewing and Editing. Qingshan Wang: Visualization, Investigation. Yuan Wang: Supervision, Software, Validation.

Funding This work was supported by the National Key Research and Development Program (2019YFB1803701) and the Research Program Fund for Humanities and Social Sciences of the Ministry of Education of China (20YJA630042). 
Data availability The data utilized to support the findings are available in the above context or from the corresponding author.

\section{Declarations}

\section{Ethics approval and consent to participate Not applicable}

Consent for publication All authors agreed with the content and that all gave explicit consent to submit.

Conflict of interest The authors declare no competing interests.

\section{References}

Arvanitopoulos T, Agnolucci P (2020) The long-term effect of renewable electricity on employment in the United Kingdom. Renewable \& Sustainable Energy Reviews. 134:110322. https://doi.org/10.1016/ j.rser.2020.110322

Bulavskaya T, Reynes F (2018) Job creation and economic impact of renewable energy in the Netherlands. Renewable Energy. 119: 528-538. https://doi.org/10.1016/j.renene.2017.09.039

Bongers A, Gómez T, Torres JL (2020) Teaching dynamic general equilibrium macroeconomics to undergraduates using a spreadsheet. International Review of Economics Education. 35:100197. https:// doi.org/10.1016/j.iree.2020.100197

Bulut U, Menegaki A (2020) Solar energy-economic growth nexus in top 10 countries with the highest installed capacity. Energy Sources Part B Economics Planning and Policy. 65:1-14. https://doi.org/10. 1016/j.scs.2020.102590

Cameron L, Bob V (2015) Employment factors for wind and solar energy technologies: a literature review. Renewable \& Sustainable Energy Reviews. 45:160-172. https://doi.org/10.1016/j.rser.2015.01.001

Celik AN, Zgür E (2020) Review of Turkey's photovoltaic energy status: legal structure, existing installed power and comparative analysis. Renewable and Sustainable Energy Reviews. 134:110344. https:// doi.org/10.1016/j.rser.2020.110344

Dga C, Fb A, Ds B, Mdb C, Nw A, Rg A (2019) The role of renewable energy in the global energy transformation - ScienceDirect. Energy Strategy Reviews. 24:38-50. https://doi.org/10.1016/j.esr.2019.01. 006

Dong C, Zhou R, Li J (2020) Rushing for subsidies: The impact of feed-in tariffs on solar photovoltaic capacity development in China. Appl Energy 281:116007. https://doi.org/10.1016/j.apenergy.2020. 116007

Duan J, Qiu X, Ma W, Tian X, Shang D (2018) Electricity consumption forecasting scheme via improved LSSVM with maximum correntropy criterion. Entropy. 20:112. https://doi.org/10.3390/ e20020112

Dvořák P, Martinát S, der Horst DV, Frantál B, Turečková K (2017) Renewable energy investment and job creation; a cross-sectoral assessment for the Czech Republic with reference to EU benchmarks. Renewable and Sustainable Energy Reviews. 69:360-368. https:// doi.org/10.1016/j.rser.2016.11.158

Feng D, Chen H (2021) A small samples training framework for deep learning-based automatic information extraction: case study of construction accident news reports analysis. Advanced Engineering Informatics 47:101256. https://doi.org/10.1016/j.aei.2021.101256

Feng Q, Sun X, Hao J, Li J (2021) Predictability dynamics of multifactorinfluenced installed capacity: a perspective of country clustering. Energy (Oxford) 214:118831. https://doi.org/10.1016/j.energy. 2020.118831
Heavner B, Chiaro DB (2003) Renewable energy and jobs: employment impacts of developing markets for renewables in California. Environment California Research and Policy Center. http://pincdn. s3.amazonaws.com/assets/A9ARLCLxDPogBKJ-oGgbRA/ Renewable Energy and Jobs.pdf

Hondo H, Moriizumi Y (2017) Employment creation potential of renewable power generation technologies: a life cycle approach. Renew Sustain Energy Rev 79:128-136. https://doi.org/10.1016/j.rser. 2017.05.039

IRENA-International Renewable Energy Agency (2018) Renewable Energy and Jobs: Annual Review 2018. Abu Dhabi. https://www. irena.org/DocumentDownloads/Publications/IRENA_RE_Jobs Annual Review 2018.pdf

Jiang Y, Lei Y, Yan X, Yang Y (2019) Employment impact assessment of carbon capture and storage (CCS) in China's power sector based on input-output model. Environ Sci Pollut Res Int. 26:1566515676. https://doi.org/10.1007/s11356-019-04928-2

Kabir E, Kumar P, Kumar S, Adelodun AA, Kim KH (2018) Solar energy: potential and future prospects. Renew Sustain Energy Rev 82: 894-900. https://doi.org/10.1016/j.rser.2017.09.094

Khan A, Chiroma H, Imran M, Khan A, Aljuaid H (2020) Forecasting electricity consumption based on machine learning to improve performance: a case study for the organization of petroleum exporting countries (OPEC). Computers \& Electrical Engineering. 86:106737. https://doi.org/10.1016/j.compeleceng.2020.106737

Li S, Yang X, Li R (2018) Forecasting China's Coal Power Installed Capacity: A Comparison of MGM, ARIMA, GM-ARIMA, and NMGM Models. Sustainability. 10:506. https://oi.org/10.3390/ su10020506

Li X, Yao X, Guo Z, Li J (2020) Employing the CGE model to analyze the impact of carbon tax revenue recycling schemes on employment in coal resource-based areas: evidence from Shanxi. Sci Total Environ 720:137191-137192. https://doi.org/10.1016/j.scitotenv. 2020.137192

Liu H, Zeng M, Pan T, Chen W, Zhang X, Huo X (2020) The green photovoltaic industry installed capacity forecast in China: based on grey relation asnalysis, improved signal decomposition method, and artificial bee colony algorithm. Mathematical Problems in Engineering. 2020:1-15. https://doi.org/10.1155/2020/9892480

Luo J, Hong T, Fang S-C (2018) Benchmarking robustness of load forecasting models under data integrity attacks. Int J Forecast 34:89 104. https://doi.org/10.1016/j.ijforecast.2017.08.004

Mahmoudi A, Javed SA, Liu S, Deng X (2020) Distinguishing coefficient driven sensitivity analysis of GRA model for intelligent decisions: application in project management. Technological and Economic Development of Economy. 26:621-641. https://doi.org/10.3846/ tede. 2020.11890

Marques AC, Fuinhas JA, Pereira DS (2019) The dynamics of the short and long-run effects of public policies supporting renewable energy: a comparative study of installed capacity and electricity generation. Economic analysis and policy. 63:188-206. https://doi.org/10.1016/ j.eap. 2019.06 .004

Mu Y, Cai W, Evans S, Wang C, Roland-Holst D (2018) Employment impacts of renewable energy policies in China: a decomposition analysis based on a CGE modeling framework. Applied Energy. 210:256-267. https://doi.org/10.1016/j.apenergy.2017.10.086

Nemet GF, Lu J, Rai V, Rao R (2020) Knowledge spillovers between PV installers can reduce the cost of installing solar PV. Energy Policy. 144:111600. https://doi.org/10.1016/j.enpol.2020.111600

Or A, Ph B, Rma C (2020) Economic implications of forecasting electricity generation from variable renewable energy sources. Renew Energy 161:1318-1327. https://doi.org/10.1016/j.renene.2020.06. 110

Panagiotis F, Leonidas P (2018) Employment creation in EU related to renewables expansion. Appl. Energy 230:935-945. https://doi.org/ 10.1016/j.apenergy.2018.09.032 
Proença S, Fortes P (2020) The social face of renewables: econometric analysis of the relationship between renewables and employment. Energy Reports. 6:581-586. https://doi.org/10.1016/j.egyr.2019.09. 029

Ram, Manish, et al. (2017) "Global energy system based on $100 \%$ renewable energy - power sector." Lappeenranta University of Technology and Energy Watch Group: Lappeenranta, Finland

Rutovitz J, Atherton A (2009) Energy Sector Jobs to 2030: A Global Analysis. Prepared for Greenpeace International by the Institute for Sustainable Futures University of Technology, Sydney. https:// opus.lib.uts.edu.au/handle/10453/20458

Rutovitz J, Dominish E, Downes J (2015) Calculating Global Energy Sector Jobs 2015 Methodology Update 2015. Prepared for Greenpeace International by the Institute for Sustainable Futures University of Technology Sydney, Sydney). https://opus.lib.uts. edu.au/handle/10453/43718

Şahin U (2020) Projections of Turkey's electricity generation and installed capacity from total renewable and hydro energy using fractional nonlinear grey Bernoulli model and its reduced forms. Sustain Prod Consum 23:52-62. https://doi.org/10.1016/j.spc.2020.04.004

Stephens JC (2019) Energy democracy: redistributing power to the people through renewable transformation. Environment 61:4-13. https://doi.org/10.1080/00139157.2019.1564212

Uniejewski B, Weron R (2021) Regularized quantile regression averaging for probabilistic electricity price forecasting. Energy Economics. 95:105121. https://doi.org/10.1016/j.eneco.2021.105121

U.S. Department of Energy (2017) U.S. Energy and Employment Report. Washington D.C. https://energy.gov/sites/prod/files/2017/01/f34/ 2017

U.S. Department of Energy. U.S. Energy and Employment Report (2021) https://energy.gov/sites/prod/files/2017/01/f34/2017 US Energy and Jobs Report_0.pdf/;2017 [Accessed 11 January 2021].

Vosniadou S, Pnevmatikos D, Makris N (2018) The role of executive function in the construction and employment of scientific and mathematical concepts that require conceptual change learning. Neuroeducation 5:62-72. https://doi.org/10.24046/neuroed. 20180502.62
Wang Q, Li S, Li R (2018) Forecasting energy demand in China and India: using single-linear, hybrid-linear, and non-linear time series forecast techniques. Energy 161:821-831. https://doi.org/10.1016/j. energy.2018.07.168

Wei G (2010) GRA method for multiple attribute decision making with incomplete weight information in intuitionistic fuzzy setting. Knowledge-Based Systems. 23:243-247. https://doi.org/10.1016/j. knosys.2010.01.003

Xu G, Schwarz P, Yang H (2019) Determining China's $\mathrm{CO}_{2}$ emissions peak with a dynamic nonlinear artificial neural network approach and scenario analysis. Energy Policy 128:752-762. https://doi.org/ 10.1016/j.enpol.2019.01.058

Yan Z, Zou B, Du K, Li K (2020) Do renewable energy technology innovations promote China's green productivity growth? Fresh evidence from partially linear functional-coefficient models. Energy Economics. 90:104842. https://doi.org/10.1016/j.eneco.2020. 104842

Zeng Y-R, Zeng Y, Choi B, Wang L (2017a) Multi-factor-influenced energy consumption forecasting using enhanced back-propagation neural network. Energy 127:381-396. https://doi.org/10.1016/j. energy.2017.03.094

Zeng Y-R, Zeng Y, Choi B, Wang L (2017b) Multifactor-influenced energy consumption forecasting using enhanced back-propagation neural network. Energy 127:381-396. https://doi.org/10.1016/j. energy.2017.03.094

Zhou S, Siriboonchitta S, Yamaka W, Maneejuk P (2020) The impact of cultural industry on economic and employment growth in China. $\mathrm{J}$ Adm Bus Stud 6. https://doi.org/10.20474/jabs-6.4.3

Zhu L et al (2019) Forming a new small sample deep learning model to predict total organic carbon content by combining unsupervised learning with semisupervised learning. Appl Soft Comput 83. https://doi.org/10.1016/j.asoc.2019.105596

Publisher's note Springer Nature remains neutral with regard to jurisdictional claims in published maps and institutional affiliations. 